\title{
Design and Economic Analysis of a Flexible Pavement on a Geosynthetic Reinforced Subgrade
}

\author{
*OGUNKUNBI, GA; JIMOH, YA \\ Department of Civil Engineering, University of Ilorin, Ilorin, Nigeria \\ *Corresponding Author Email: gaogunkunbi@gmail.com,Tel: +2347033953862; Other Email: yaj@unilorin.edu.ng
}

\begin{abstract}
This study investigated the effect of geogrid reinforcement on the mechanical property of an unsuitable road soil with respect to appropriate placement in the pavement structure and implication on the cost of the development of the road. Sample was collected from the stockpile of an unsuitable soil material at a bridge site and subjected to identification, geotechnical strength (CBR) and chemical stabilization tests. CBR strength evaluation test was further performed on the soil sample when reinforced with the use of a geosynthetic, triaxial geogrid (Tx 160). A flexible pavement structure was designed for low, medium and heavy traffic level using three design methods with the improved soil subgrade. The corresponding relative cost advantages were also determined using the pavement thickness reduction factor. The results established the geogrid reinforcement is a better alternative to chemical stabilization of an unsuitable AASHTO A-4 soil. The design results denoted a significant pavement thickness reduction factor as a result of geogrid reinforcement within 13\% - 67\% savings in pavement thickness for all the pavement design methods employed. The use of geogrids should, therefore, be encouraged as an economic form of improving subgrade soils for pavement works.
\end{abstract}

\section{DOI: https://dx.doi.org/10.4314/jasem.v23i1.18}

Copyright: Copyright (C) 2019 Ogunkunbi and Jimoh. This is an open access article distributed under the Creative Commons Attribution License (CCL), which permits unrestricted use, distribution, and reproduction in any medium, provided the original work is properly cited.

Dates: Received: 17 October 2018; Revised: 05 January 2019; Accepted 17 January 2019

Keywords: geogrid, flexible pavement, chemical stabilization

Highways as a fixed facility component of a transportation system dominate the means of transportation in many countries of the world, as either rigid or flexible pavement. As a matter of necessity, a sound and economic pavement layer is derivable from soils with desirable engineering qualities like good bearing capacity and good drainage, among others as the structural components of the pavement; including the subgrade which is the foundation. Subgrade supports the pavement to carry load and hence should have adequate strength. Pavement structural design with weaker soil subgrade implies an increased pavement thickness for a specified traffic level, thereby adding to cost. Natural soil is of limited strength in many places. Information contained in research reports provided by the Nigerian Building and Road Research Institute on the engineering properties of subgrade soils indicated that $48 \%, 53 \%$ and $74 \%$ of subgrade soils found in Imo State (Omange et al., 1988), old Bendel State (Omange and Aitsebaomo, 1989) and Lagos State (Omange et al., 1987) respectively were found to be poor subgrade soils as they belong within the range of A-4 and A-8 soils. A review of problem soils in Nigeria by Bolarinwa and Ola (2016) also showed a large deposit of soils with undesirable engineering properties across the country including Ilorin, the Kwara State capital. There is, therefore, an evidence of the domineering existence of poor engineering soils in the nation and implies that pavement design would be problematic and inadequate in such areas because of associated challenges in sourcing construction materials. Cost associated with poor subgrades include relatively larger sub-base and base thicknesses, right-of-way purchases as a result of the relocation of road corridors and eventually longer construction periods with associated opportunity costs. In the construction and maintenance of transportation facilities, geomaterials-soils and rocks- of inadequate natural strength must be stabilised through chemical and/or mechanical processes. Soil stabilisation aims at improving soil strength and increasing resistance to softening by water through bonding the soil particles together, waterproofing the particles or combination of the two (Sherwood, 1993). Therefore, in order to avoid change of alignment, uneconomical design and construction time, if accomplished with chemical means of stabilisation, and to prevent the emergence of unfavourable worker's health hazards associated with chemical stabilisation, some other means of ground improvement becomes necessary. In this study, the suitability and effectiveness of geosynthetic materials, especially geogrids because of its primary reinforcement and separation function, in the improvement of poor soils at its worst state (that is when it is soaked) is examined as an alternate but

*Corresponding Author Email: gaogunkunbi@gmail.com, Tel: +2347033953862; Other Email:

yaj@unilorin.edu.ng 
feasible means of making the erstwhile unsuitable road soil suitable for pavement works as the road subgrade, subbase or even road base. The objective of this study is to investigate the effect of geogrid reinforcement on the mechanical property of an unsuitable road soil with respect to appropriate placement in the pavement structure and implication on the cost of the development of the road.

\section{MATERIALS AND METHODS}

Soil Sample: The soil sample used for the laboratory investigations was collected from the stockpile of soil that was meant to be hauled away from the Omosebi bridge construction site in Ilorin, Nigeria due to its unsuitability for bridge and roadworks. The location map is shown in Figure 1. The soil samples were moved to the laboratory protected to preserve the natural state. Analysis was then carried out to ascertain the physical and engineering properties of the sample.

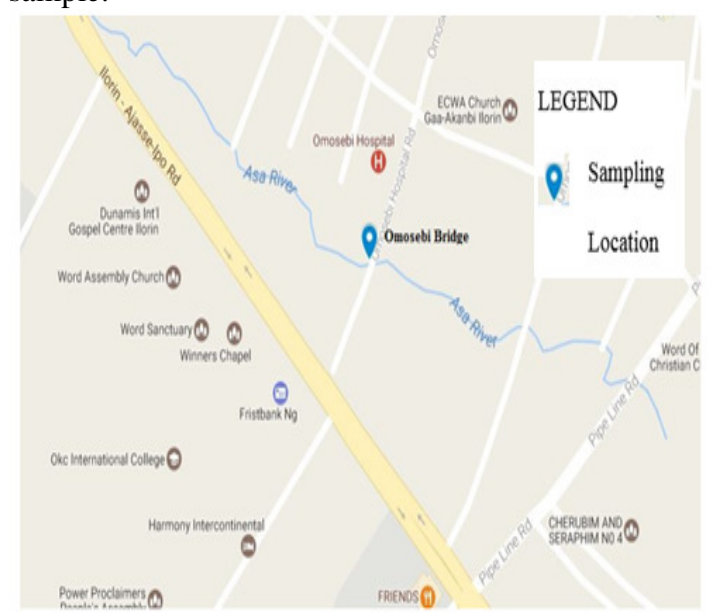

Fig 1: Google Map Imagery of the Sampling Location (Omosebi Bridge)

Geosynthetics: Geosynthetics are synthetic materials manufactured from polymers of polyethylene, polypropylene or polyester and used in earthwork improvements. According to the International Geosynthetics Society (IGS), the geosynthetic materials used in the asphalt paving industry are geocomposite, geogrid, geomembrane, geomat and geotextile and are employed in different situations. For the purpose of this study, geogrid was used since soil reinforcement is required as it is known to perform the functions of reinforcement and separation. The geogrid used, Triax TX-160 was obtained from MacGeorge Nigeria Limited, Lagos and its specifications are shown in Table 1.

Preliminary Laboratory Investigation: The sample was air-dried and subjected to a comprehensive laboratory programme for roadworks. The tests were carried out with the standard equipment and test procedures as described in BS 1377 (BSI, 1990) with classification in accordance with Unified Soil Classification System and AASHTO. The tests carried out on the representative samples include sieve analysis, Atterberg limits, compaction, specific gravity and California Bearing Ratio (CBR) with and without the geogrid reinforcement or another stabiliser.

Table 1: Geogrid Triax TX-160 Properties

\begin{tabular}{ll}
\hline Index Properties & \\
\hline Rib Pitch (Longitudinal and Transverse) & $40.0 \mathrm{~mm}$ \\
Diagonal midrib depth & $1.6 \mathrm{~mm}$ \\
Diagonal midrib width & $1.0 \mathrm{~mm}$ \\
Rib shape & Rectangular \\
Aperture shape & Triangular \\
\hline Structural Integrity & $93 \%$ \\
\hline Junction efficiency & $300 \mathrm{kN} / \mathrm{m}$ \\
Radial stiffness at 0.5\% strain & $100 \%$ \\
\hline Durability & $70 \%$ \\
\hline Resistance to chemical degradation \\
Resistance to UV light \& weathering
\end{tabular}

Geogrid Reinforcement: The experimental study involved performing a series of laboratory CBR tests on the geogrid reinforced soil. The geogrid was interfaced between different layers (that is between layers $1-2,2-3,3-4$ and $4-5$ ) of the soil in the CBR mould (Figure 2) to determine the optimum location of reinforcement for both unsoaked and soaked conditions.

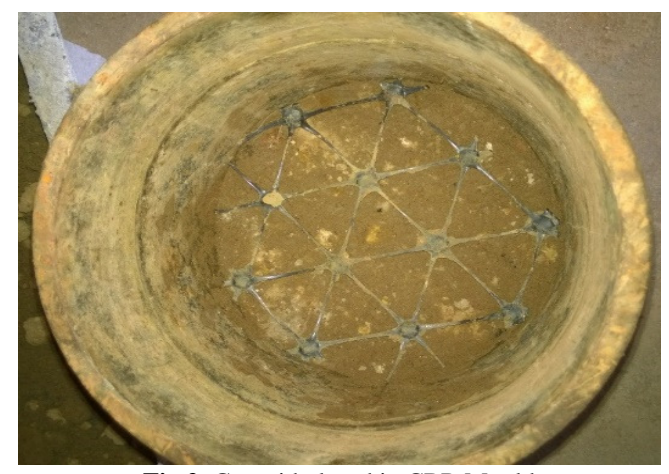

Fig 2: Geogrid placed in CBR Mould

Chemical Stabilisation: The soil sample was stabilised based on the results of the preliminary tests. Increasing percentages (by weight of dry soil) of the modifier were added and mixed thoroughly with the soil. The soil-modifier mixes so prepared were covered and left to mellow for the required periods before Compaction and CBR tests were performed on them in accordance with the specifications of BS 1924 (BSI, 1990).

Flexible Pavement Design: In order to assess the effect of the geogrid reinforcements on pavement layer 
thickness design, the Overseas Road Note (ORN) 31, AASHTO 1993 and Asphalt Institute methods were used for the three design traffic level. The layer thicknesses for the subgrade sample without geogrid, when chemically stabilised, as well as the subgrade sample with Triax Tx 160, were also designed. For the Asphalt Institute and AASHTO 1993 method, the CBR values were converted to resilient modulus, $M_{R}$ for subgrade based on the conversion factors included in NCHRP Report 128 (Van Til et al., 1972) as shown in Equation 1.

$$
M_{R}=1941.488 \times C B R^{0.6844709}
$$

The input parameters used for the design of the pavement section are given:

a. Traffic Level: Low $=0.25$ million equivalent standard axles (mesa); Medium $=5$ million equivalent standard axles (mesa); Heavy $=15$ million equivalent standard axles (mesa)

b. $\quad$ Unreinforced section: Subgrade CBR $=10 \%$; Resilient Modulus of Subgrade $=9389$ psi $(64.73$ $\mathrm{MPa}$ )

c. $\quad$ Reinforced section: Subgrade CBR $=56 \%$; Resilient Modulus of Subgrade $=30529$ psi $(210.49$ $\mathrm{MPa}$ )

d. Chemically stabilized section: Subgrade $\mathrm{CBR}=34 \%$; Resilient Modulus of Subgrade $=21696$ psi (149.59 MPa)

e. AASHTO specific design parameters: Reliability $=90 \%$; Standard Deviation $=0.45$; Initial Serviceability $=4.5$; Terminal Serviceability $=2.5$; Layer and Drainage Coefficient - Base $=0.14$ and 1.00; Layer and Drainage Coefficient - Sub-base = 0.11 and 0.80; Minimum Base Thickness $=100 \mathrm{~mm}$

The percentage savings in pavement thickness were computed using Equation 2.

$\%$ SPT $=\frac{\text { TUFPT-TRFPT }}{\text { TUFPT }} \times 100 \%$

SPT $=$ Savings in Pavement Thickness; TUFPT = Total Unreinforced Pavement Thickness; TRFPT = Total Reinforced Pavement Thickness

\section{RESULTS AND DISCUSSION}

The summary of the preliminary test results is presented in Table 2. The results show that the soil sample is a poorly graded silty sand which belongs to the A-4 AASHTO class and is thus rated as a fair subgrade soil. This soil type is not recommended for use as subgrade for road construction works according to the Federal Ministry of Works and Housing (1997) specifications, which requires not more than $35 \%$ of particles passing through sieve 200 (soils belonging to A-1 and A-2 AASHTO subgroups), except the soil is subjected to modification or stabilisation. This justifies the subsequent reinforcement with geogrid and stabilisation experiments the soil was subjected to.

Table 2: Summary of Preliminary Test Results

\begin{tabular}{lc}
\hline \multicolumn{1}{c}{ Test } & Result \\
\hline Sieve Analysis & \\
$\%$ Gravel & 13.8 \\
$\%$ Sand & 50.6 \\
$\%$ Silt - Clay & 35.6 \\
\hline Specific Gravity & 2.58 \\
\hline Atterberg Limits \\
Liquid Limit \\
Plastic Limit \\
Plasticity Index & 21.00 \\
\hline Compaction & 16.52 \\
Maximum Dry Density $\left(\mathrm{gcm}^{-3}\right)$ & 4.48 \\
Optimum Moisture Content $(\%)$ & \\
\hline California Bearing Ratio & 1.984 \\
Unsoaked (\%) & 8.75 \\
Soaked (\%) & 25 \\
\hline AASHTO Classification & 10 \\
\hline
\end{tabular}

The results of the CBR tests when the sample was reinforced with the geogrid for the unsoaked and soaked condition at different depths within the CBR mould are presented in Table 3 . The results show that there was an increase in the CBR values under unsoaked $(25 \%-74 \%)$ and soaked $(10 \%-56 \%)$ conditions. The CBR increased as a result of the interlock of aggregates between the apertures of the geogrid and thus creates a lateral restraint in the soil which helps to enhance the vertical stress distribution exerted on the subgrade. The maximum resistance to the plunger penetration was exhibited by the sample when the geogrid was interfaced with the soil at layer 3 . Hence, the layer is the optimum position for the geogrid to achieve maximum resistance.

Table 3: Summary of CBR Results after Reinforcement

\begin{tabular}{llll}
\hline Position & Layer & $\begin{array}{l}\text { Unsoaked } \\
\text { CBR }\end{array}$ & $\begin{array}{l}\text { Soaked } \\
\text { CBR }\end{array}$ \\
\hline 0 & Without & 25 & 10 \\
1 & Geogrid & & 26 \\
2 & $1-2$ & 49 & 38 \\
3 & $2-3$ & 63 & 56 \\
4 & $3-4$ & 74 & 30 \\
\hline
\end{tabular}

As shown in Table 4, the $460 \%$ increase in the CBR of the soil under soaked condition when reinforced with geogrid at the mid-layer has improved the soil from just being used as a subgrade material but also to be useful as a subbase in pavement works based on the specifications of Federal Ministry of Works and Housing (1997). 
Table 4: CBR Results showing Percentage Increase

\begin{tabular}{|c|c|c|c|c|}
\hline & \multicolumn{2}{|c|}{ Unsoaked } & \multicolumn{2}{|l|}{ Soaked } \\
\hline & $\begin{array}{l}\text { CBR } \\
(\%)\end{array}$ & $\begin{array}{l}\text { Percentage } \\
\text { increase in } \\
\text { CBR }(\%)\end{array}$ & $\operatorname{CBR}(\%)$ & $\begin{array}{l}\text { Percentage } \\
\text { increase in } \\
\text { CBR }(\%)\end{array}$ \\
\hline $\begin{array}{l}\text { Without } \\
\text { Geogrid }\end{array}$ & 25 & - & 10 & - \\
\hline $\begin{array}{l}\text { With Triax } ® \text { Tx } \\
160\end{array}$ & 74 & 196 & 56 & 460 \\
\hline
\end{tabular}

As the soil exhibited low plasticity based on the Atterberg limits test (plasticity index of $4.48 \%$ ), it was stabilised using Portland Limestone Cement (PLC) in consonance with the recommendation of Section 6.2.1 of the Nigerian Highway Manual, Part 1, Volume III (Federal Ministry of Works, 2013). The results of the compaction and CBR tests with increasing percentage PLC content by weight of dry sample are presented in Table 5. The results show that there was an increase in maximum dry density with increasing percentage PLC. However, the optimum moisture content increased up till 4\% PLC content after which the optimum moisture content started declining. These, together with the increase in CBR from $10 \%$ to $65 \%$ due to the chemical stabilisation indicates the soil to be a good material for cement stabilisation as the process has improved the soil and made it suitable for use as a subbase material. The CBR also exhibited linear increase with increasing percentage content of Portland limestone cement for unsoaked and soaked condition respectively as shown in Figure 4. The Federal Ministry of Works (2013), however, recommends not more than 5\% cement content for pavement works which gives corresponding CBR values of $58 \%$ and $34 \%$ for unsoaked and soaked conditions respectively.

\begin{tabular}{llllll}
\multicolumn{6}{c}{ Table 5: Results of Chemical Stabilisation } \\
\hline $\begin{array}{l}\text { \% PLC } \\
\text { CONTENT }\end{array}$ & $\begin{array}{l}\text { Maximum Dry } \\
\text { Density }\left(\mathrm{gcm}^{-3}\right)\end{array}$ & $\begin{array}{l}\text { Optimum } \\
\text { Moisture } \\
\text { Content }(\%)\end{array}$ & $\begin{array}{l}\text { Unsoaked } \\
\text { CBR }(\%)\end{array}$ & $\begin{array}{l}\text { Soaked } \\
\text { CBR } \\
(\%)\end{array}$ \\
\hline 0 & 1.98 & 8.8 & 25 & 10 \\
2 & 1.99 & 9.8 & 34 & 14 \\
4 & 2.00 & 10.0 & 49 & 23 \\
6 & 2.02 & 7.1 & 60 & 36 \\
7 & 2.02 & 6.8 & 68 & 44 \\
9 & 2.05 & 6.8 & 97 & 65 \\
\hline
\end{tabular}

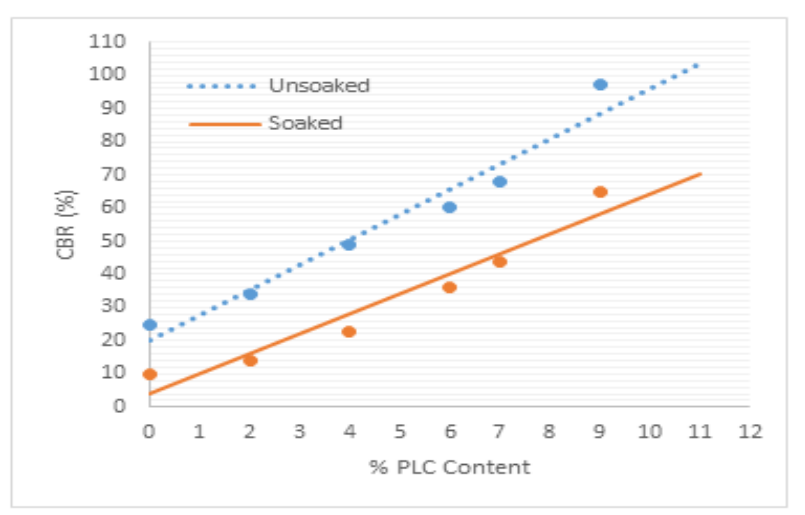

Fig 4: Variation of CBR with PLC content

Based on the linear relationship between the CBR value and the percentage PLC content as exhibited in Figure 4, it can be deduced that $7.1 \%$ and $8.6 \%$ of Portland limestone cement will be required to match the CBR values obtained for the geogrid reinforcement for unsoaked $(74 \%)$ and soaked $(56 \%)$ conditions respectively. This shows that the cement content that is required exceeds the $5 \%$ cement content recommended by Federal Ministry of Works (2013) and thus makes the soil-cement mixture susceptible to cracking. The geogrid reinforcement, therefore, assures more durability (less susceptibility to cracking) in structural integrity and an extended pavement service life as cracking in the chemical stabilized soil caused by high cement content is avoided while saving time and reducing the carbon footprint during the pavement construction.

For the Overseas Road Note 31 Method of pavement design, the traffic levels and subgrade CBR were classified as described by ORN 31(Transport Research Laboratory, 1993). The appropriate pavement layer thicknesses were selected from the ORN 31 charts for a granular roadbase with minimum base course thickness of $150 \mathrm{~mm}$ as shown in Table 6. To design using the Asphalt Institute method, a uniform untreated granular base thickness of $150 \mathrm{~mm}$ was assumed for all sections. The appropriate pavement layer thicknesses corresponding to the resilient modulus and traffic levels were selected from the Asphalt Institute charts as presented in Nigerian Highway Manual, Part 1, Volume III (Federal Ministry of Works, 2013) and are shown in Table 7. For the AASHTO 1993 method, the appropriate pavement layer thicknesses were determined using the input parameters and AASHTO 1993 flexible pavement design equations (Transport Officials, 1993). The results obtained are presented in Table 8 . The summary of the percentage reduction in pavement thickness designed by the three approaches as a result of the geogrid reinforcement is presented in Table 9. 
Table 6: Pavement Layers Thickness (ORN 31)

\begin{tabular}{|c|c|c|c|c|}
\hline \multirow{3}{*}{$\begin{array}{l}\text { Design } \\
\text { Traffic }\end{array}$} & & Unreinforced & Reinforced & \multirow{3}{*}{$\begin{array}{l}\text { Percentage } \\
\text { Savings in } \\
\text { Pavement } \\
\text { Thickness }\end{array}$} \\
\hline & CBR & 10 & 56 & \\
\hline & $\begin{array}{l}\text { Subgrade } \\
\text { Class }\end{array}$ & S4 & S6 & \\
\hline \multirow{2}{*}{$\begin{array}{l}\text { T1 } \\
(0.25 \\
\text { mesa) }\end{array}$} & Base & $150 \mathrm{~mm}$ & $150 \mathrm{~mm}^{* *}$ & \multirow[b]{2}{*}{45.5} \\
\hline & Subbase & $125 \mathrm{~mm}$ & - & \\
\hline $\begin{array}{l}\text { T5 (5 } \\
\text { mesa) }\end{array}$ & $\begin{array}{l}\text { Base } \\
\text { Subbase }\end{array}$ & $\begin{array}{l}200 \mathrm{~mm} \\
250 \mathrm{~mm}\end{array}$ & $\begin{array}{l}150 \mathrm{~mm} \\
-\end{array}$ & 66.7 \\
\hline $\begin{array}{l}\text { T7 (15 } \\
\text { mesa) }\end{array}$ & $\begin{array}{l}\text { Base* } \\
\text { Subbase }\end{array}$ & $\begin{array}{l}375 \mathrm{~mm} \\
175 \mathrm{~mm}\end{array}$ & $\begin{array}{l}125 \mathrm{~mm} \\
225 \mathrm{~mm}\end{array}$ & 36.4 \\
\hline
\end{tabular}

* - Combination of bituminous roadbase $(150 \mathrm{~mm})$ and granular roadbase $(225 \mathrm{~mm})$; ** Recommended minimum base course thickness for ORN31

\begin{tabular}{lllll}
\multicolumn{4}{c}{ Table 7: Pavement Layers Thickness (Asphalt Institute) } \\
\hline \multirow{2}{*}{$\begin{array}{l}\text { Design } \\
\text { Traffic }\end{array}$} & $\begin{array}{l}\text { Resilient } \\
\text { Modulus } \\
(\mathrm{psi})\end{array}$ & 9389 & 30529 & $\begin{array}{l}\text { Unreinforced } \\
\begin{array}{l}\text { Savings in } \\
\text { Pavement } \\
\text { Thickness }\end{array}\end{array}$ \\
\hline 0.25 & Base & $150 \mathrm{~mm}$ & $150 \mathrm{~mm}$ & 58.3 \\
mesa & Subbase & $110 \mathrm{~mm}$ & - & 25.9 \\
\hline 5 mesa & Base & $150 \mathrm{~mm}$ & $150 \mathrm{~mm}$ & $193 \mathrm{~mm}$ \\
& Subbase & $279 \mathrm{~mm}$ & $150 \mathrm{~mm}$ & 12.8 \\
\hline 15 & $\begin{array}{c}\text { Base* } \\
\text { mesa }\end{array}$ & $\begin{array}{c}150 \mathrm{~mm} \\
320 \mathrm{~mm}\end{array}$ & $260 \mathrm{~mm}$ & \\
\hline
\end{tabular}

\begin{tabular}{|c|c|c|c|c|}
\hline \multirow[b]{2}{*}{$\begin{array}{l}\text { Design } \\
\text { Traffic }\end{array}$} & & Unreinforced & Reinforced & \multirow{2}{*}{$\begin{array}{l}\text { Percentage } \\
\text { Savings in } \\
\text { Pavement } \\
\text { Thickness }\end{array}$} \\
\hline & $\begin{array}{l}\text { Resilient } \\
\text { Modulus } \\
\text { (psi) }\end{array}$ & 9389 & 30529 & \\
\hline $\begin{array}{l}0.25 \\
\text { mesa }\end{array}$ & $\begin{array}{l}\text { Base } \\
\text { Subbase }\end{array}$ & $\begin{array}{l}100 \mathrm{~mm} \\
64 \mathrm{~mm}\end{array}$ & $\begin{array}{l}100 \mathrm{~mm}^{*} \\
-\end{array}$ & 39.0 \\
\hline 5 mesa & $\begin{array}{l}\text { Base } \\
\text { Subbase }\end{array}$ & $\begin{array}{l}250 \mathrm{~mm} \\
245 \mathrm{~mm}\end{array}$ & $\begin{array}{l}100 \mathrm{~mm} \\
86 \mathrm{~mm}\end{array}$ & 62.4 \\
\hline $\begin{array}{l}15 \\
\text { mesa }\end{array}$ & $\begin{array}{l}\text { Base* } \\
\text { Subbase }\end{array}$ & $\begin{array}{l}300 \mathrm{~mm} \\
365 \mathrm{~mm}\end{array}$ & $\begin{array}{l}150 \mathrm{~mm} \\
150 \mathrm{~mm}\end{array}$ & 54.8 \\
\hline
\end{tabular}

\begin{tabular}{|c|c|c|c|}
\hline \multirow[b]{2}{*}{ Traffic Level } & \multicolumn{3}{|c|}{ Pavement Design Method } \\
\hline & ORN 31 & Asphalt Institute & $\begin{array}{l}\text { AASHTO } \\
1993\end{array}$ \\
\hline Low & $45.5 \% *$ & $58.3 \%$ & $39.0 \% *$ \\
\hline Medium & $66.7 \%$ & $25.9 \%$ & $62.4 \%$ \\
\hline Heavy & $36.4 \%$ & $12.8 \%$ & $54.8 \%$ \\
\hline
\end{tabular}

Conclusion: The reinforcement of the silty soil with geogrid caused an increase in the California Bearing Ratio of the soil which produced a corresponding reduction in pavement thickness. These results also establish that the percentage reduction in pavement thickness is inversely proportional to the traffic volume. This principally confirms that geogrid reinforcement would be helpful in dealing with relatively poor subgrade materials by improving the strength and thus provide a less costly pavement with respect to the volume of aggregates used for construction.

\section{REFERENCES}

Bolarinwa, A; Ola, SA (2016). A Review of the Major Problem Soils in Nigeria. FUOYE J. Engineer. Technol. 1(1), pp. 20-25.

British Standard Institution (BSI) (1990). Methods of Test for Soils for Civil Engineering Properties (BS 1377). British Standard Institution: London, UK.

British Standard Institution (BSI) (1990). Stabilized materials for civil engineering purposes (BS 1924). British Standard Institution: London, UK.
Federal Ministry of Works and Housing (1997). General Specifications (Roads and Bridges). Volume II, Federal Ministry of Works and Housing, Abuja.

Federal Ministry of Works (2013). Highway Manual: Pavement and Materials Design. Part 1, Volume III.

Omange, GN; Nnama, SK; Aitsebaomo, FO (1987). Engineering Properties of Subgrade Soils in the Federal Capital Territory of Nigeria. Nigerian Building and Road Research Institute Report No. 13, Lagos.

Omange, GN; Nnama, SK; Aitsebaomo, FO (1988). Engineering Properties of Subgrade Soils in Imo State. Nigerian Building and Road Research Institute Report No. 13, Lagos.

Omange, GN; Aitsebaomo, FO (1989). Engineering Properties of Subgrade Soils in Bendel (Delta and Edo) State of Nigeria. Nigerian Building and Road Research Institute Report No. 18, Lagos.

Sherwood, P (1993). Soil stabilization with cement and lime. State of the Art review. Transport Research Laboratory, London.

Transportation Officials (1993). AASHTO guide for design of pavement structures, 1993. AASHTO, Vol. 1.

Transport Research Laboratory (1993). Overseas Road Note 31: A Guide to the Structural Design of BitumenSurfaced Roads in Tropical and SubTropical Countries ORN31. Transport Research Laboratory, Berkshire.

Van Til, CJ; McCullough, BF; Vallerga, BA; Hicks, RG (1972). NCHRP Report 128: Evaluation of AASHO Interim Guides for Design of Pavement Structures. Transportation Research Board, Washington, DC. 
